\title{
Lack of workplace mental health resources increases pressure on health care system
}

A s many as $44 \%$ of Canadian employees have experienced a mental health issue in the workplace, and those who lack support or resources from employers are more likely to seek it from the health care system, says a report from the Conference Board of Canada.

The report, "Building Mentally Healthy Workplaces: Perspectives of Canadian Workers and Front-Line Managers," includes data from a survey of more than 1000 employees, including some in the health care sector (www.con ferenceboard.ca/documents.aspx?did=42 87.) The survey included 479 front-line managers, and the report's authors also conducted 30 in-depth interviews.

Among the report's findings are that only $22 \%$ of employees surveyed received any information about mental health from their employers. Less than a third of people who identified themselves as experiencing mental health issues went on to access resources through their employers.

The Conference Board, a not-forprofit applied research organization, categorized mental health issues as including excessive stress, anxiety, depression, burnout, addictions, substance abuse, mania, bipolar and schizophrenia disorders, among other conditions. Stigma and a lack of trust about the privacy of their health information were among the barriers to accessing resources at work that employees reported.

The report suggested that the health care community is critical to providing employees with proper mental health care: $49 \%$ said they would first seek help from their doctors or other health care providers for any mental health issue. The survey also pointed to the essential role, however, that workplaces can play in reducing the burden on the health care system.

Of those employees who did access workplace supports, only $66 \%$ also went to a doctor or other health care

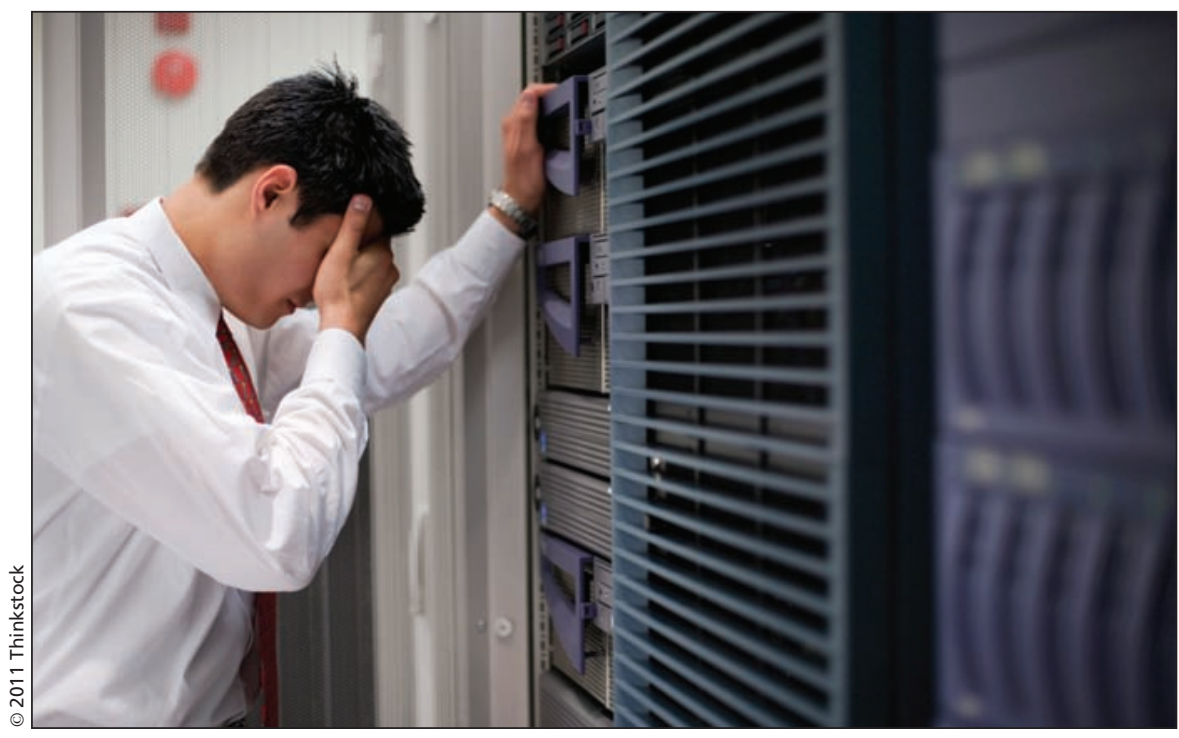

Though many employees experience mental health issues on the job, including excessive stress, anxiety and depression, only $22 \%$ of employees in a recent survey received any information about mental health from their employers.

provider for help, compared to $82 \%$ of those who did not access workplace supports.

"What this does show is that having resources and supports available in the workplace can change people's behaviour and where they get outside resources," says Karla Thorp, associate director at the Conference Board and coauthor of the report.

"Clearly, one of our recommendations to employers is they need to communicate with employees more about mental health issues. They need to educate them more about the resources that are available."

The prevalence of mental health issues is surprising, says Thorp. Previous studies have reported one out of every five Canadians will face a mental health issue in his or her lifetime (www.phac-aspc.gc.ca /publicat/human-humain06/pdf/human _face_e.pdf). She attributed the higher levels reported by the survey in part to the broad definition the Conference Board used.

Another surprise for the authors was the gap between managers' self-assess- ments of how comfortable they were talking to employees about mental health and employees' perceptions of their managers' comfort in this area. While most managers said they felt confident talking to their staffs about these issues, most employees said they would not feel comfortable talking to their managers, and rated them as less knowledgeable than the managers rated themselves. The report highlights the importance of providing managers with more training and information about community resources, beyond supports through Employee Assistance Programs.

One such resource is Mental Health Works, a program run by the Canadian Mental Health Association. The awardwinning program provides management skills training and helps employees understand their own stress responses, as well as recognize issues their colleagues might be experiencing. Trainers work with employers and employees to support people returning from work after disability leaves for mental health issues.

Donna Hardaker codesigned the 
program for the Canadian Mental Health Association, which she says she based on her own experience of fighting debilitating depression and anxiety while working.

Managers are often frustrated because they can't apply the same approach to an employee returning after a mental health issue as they would to someone returning after a physical health problem, says Hardaker. "What we train people to do is about having effective conversations with an employee."

Often, employers don't realize they have a duty to accommodate an employee's needs. Those accommodations can be as simple as giving people written instructions instead of verbal ones or, if they are having trouble concentrating, changing fluorescent lighting to lamps.

A huge part of the work Hardaker and other trainers do is to help break down the stigma surrounding mental illness, she adds. "It's to help people feel connected to someone who has a mental illness ... as opposed to just seeing someone as a problem, or as weak, or as someone to just get rid of."

Employers need access to more resources about mental health and what they can do for their employees, says Mary Ann Baynton, a consultant and member of the Mental Health Commission of Canada's Workforce Advisory Committee.
That's why Baynton is working with the commission to develop a national standard for psychology health and safety. The standard is intended to help employers and unions put preventative approaches in place to reduce mental illness.

"Just like a safe work environment would not cause physical harm, a psychologically safe workplace would not cause psychological harm," says Baynton.

The national standard will be voluntary, she says, and is intended as a support and a roadmap rather than an additional burden for employers. - Laura Eggertson, Ottawa, Ont.

CMAJ 2011. DOI:10.1503/cmaj.109-3945 